\title{
Small-scale variability in the dispersion of the sea urchin Heliocidaris erythrogramma among boulders
}

\author{
A. F. Smoothey*, M. G. Chapman \\ Centre for Research on Ecological Impacts of Coastal Cities, Marine Ecology Laboratories A11, University of Sydney, \\ New South Wales 2006, Australia
}

\begin{abstract}
Densities of many organisms, particularly invertebrates, are inherently patchy from place to place, with much variability at small spatial scales. Intertidal and shallow subtidal boulder fields in New South Wales, Australia, support a diverse suite of species, many of which have very patchy distributions among boulders. In this study, the purple urchin Heliocidaris erythrogramma was very patchily distributed at small spatial scales, being abundant under some boulders and absent from others. This pattern was found consistently at different times and in boulder fields tens of kilometres apart. Experiments were done to identify mechanism(s) that may establish and maintain the observed distribution. Small-scale variability in distribution was established early in the animals' life-cycle, because Heliocidaris recruits were more abundant on boulders with adult urchins than on boulders without adult urchins. Manipulative experiments indicated that the pattern of dispersion was also maintained by the behavioural responses of juvenile and adult urchins to either feature(s) of boulders or to cues associated with conspecifics. When Heliocidaris were transplanted to boulders originally without urchins, they left at a greater rate than did urchins on boulders that originally had urchins but from which urchins had been removed. In addition, juvenile and adult urchins colonised more boulders with urchins than boulders without urchins. Behavioural responses to unidentified but specific requirements of habitat provided by some boulders may thus be important in maintaining non-random densities of urchins among boulders.
\end{abstract}

KEY WORDS: Boulder field - Sea urchin - Heliocidaris - Small-scale · Movement - Recruitment . Dispersion $\cdot$ Subtidal $\cdot$ Intertidal

\section{INTRODUCTION}

Spatial and temporal patchiness is an inherent feature of assemblages in freshwater, terrestrial and marine environments (Wiens et al. 1993, Underwood \& Chapman 1996, Downes et al. 2000a). In recent years, several studies have emphasised that variation in the distribution and abundance of organisms does not occur at a single scale, but rather at a hierarchy of different spatial scales (e.g. Morrisey et al. 1992, Beisel et al. 1998). Moreover, a large amount of variation in abundances of species occurs at very small spatial scales (Underwood \& Chapman 1996, Archambault \& Bourget 1996).

In the past, variability in the abundance of intertidal organisms was thought to be governed primarily by broad environmental gradients, such as height above sea-level or exposure to wave-action (Connell 1972). It has since become apparent that physical stresses associated with broad environmental gradients cannot, on their own, describe patterns of abundance of many intertidal organisms (Underwood 1984, BenedettiCecchi 2000). Thus, intertidal ecologists are increasingly recognising the importance of the complex interaction of large-scale factors with local, small-scale processes in regulating intertidal assemblages (Menge \& Olson 1990).

Small-scale environmental variation is a feature of many habitats, such as rocky shores (e.g. Paine \& Levin 1981) and can lead to a complex array of microhabitats within an area of a few metres. Microhabitats often influence small-scale patterns of distribution and abun- 
dance of organisms, as many species are aggregated in some microhabitats and absent from others. Organisms may respond to physical features of habitat, e.g. topographic complexity (Raffaelli \& Hughes 1978, Moran 1985), and/or to biogenic structures, e.g. sessile organisms such as algae (Worthington \& Fairweather 1989).

Causes of variable dispersion of organisms may be categorised into 3 broad classes of models: patterns of birth/immigration, differential rates of emigration or mortality, or behavioural responses to habitat or conspecifics within a patch (e.g. Underwood \& Denley 1984). These models may act independently or in combination to explain the pattern under investigation. Spatial and temporal variability in settlement of marine invertebrates can be important in regulating recruitment and can vary at a range of scales, from metres to hundreds of kilometres (Balch \& Scheibling 2000, Jenkins et al. 2000) and from days to years (Loosanoff 1964, Jenkins et al. 2000). Recruitment is the result of processes affecting settlement, coupled with early post-settlement mortality (for review see Hunt \& Scheibling 1997) and/or migration of juveniles that occurs prior to the first census (Keough \& Downes 1982). Due to the inherent difficulty associated with obtaining an accurate measure of settlement and the need to sample at frequent intervals to avoid confounding patterns of settlement from patterns affected by early post-settlement processes (Keough \& Downes 1982), most studies have measured patterns of recruitment rather than patterns of settlement. After settlement, patterns can be modified by subsequent mortality of adults (e.g. Connell 1961), or mobile animals may move to establish associations with particular microhabitats (e.g. Crowe 1996).

Distributions and abundances of organisms living in boulder fields are extremely variable at small spatial scales, because many species found under boulders are not often found in adjacent habitats and/or because many are extremely aggregated (Smith \& Otway 1997, Chapman 2002a,b, Grayson \& Chapman 2004). These species are often extremely patchy at a hierarchy of spatial scales, from among different boulder fields to among individual boulders, with most variation at the scale of individual boulders within a site (Smith \& Otway 1997, Chapman 2002a, 2005, Grayson \& Chapman 2004).

Relatively little is known about the ecology and distribution of sea urchins inhabiting boulder fields, even though they are a conspicuous and abundant member of benthic marine assemblages and their ecological importance has been documented in different habitats (e.g. Benedetti-Cecchi \& Cinelli 1995) and in many geographical locations (e.g. Andrew \& Underwood 1989, Bulleri et al. 1999). We evaluated the model that the sea urchin Heliocidaris erythrogramma (hereafter
Heliocidaris) has an aggregated distribution under boulders. Most studies on the dispersion of mobile organisms in boulder fields have been about molluscs (Smith \& Otway 1997, Chapman 2002a,b, 2005, Grayson \& Chapman 2004), although Chapman (2002a) found that the sea star Patiriella exigua was very patchily distributed among boulders. In addition, we used manipulative field experiments to examine models that may explain the dispersion of Heliocidaris, specifically investigating: (1) patterns of recruitment and (2) behavioural responses of post-recruit urchins to different types of boulders.

\section{MATERIALS AND METHODS}

This study was conducted in 3 intertidal to shallow subtidal boulder fields in New South Wales, Australia: the Cape Banks Scientific Marine Research Area (hereafter referred to as Cape Banks), Clovelly Bay and Long Reef Aquatic Reserve (hereafter referred to as Long Reef; Fig. 1). The boulder field at Cape Banks is sheltered from direct wave-action except during rough seas and has been described previously by Chapman \& Underwood (1996) and Grayson \& Chapman (2004). The area used in this study was similar to that described in Chapman \& Underwood (1996) and Grayson \& Chapman (2004). The boulder field at Clovelly Bay is sheltered from direct wave-action, except during rough seas. The boulders are composed mostly of sandstone and, like those at Cape Banks, rest on bedrock, overlaid by shell grit, sand or small patches of algal turf (Grayson \& Chapman 2004). The headland of Long Reef is surrounded by an extensive rock platform with small, sandy beaches and boulder fields (Smith \& Otway 1997, Chapman 2005). Sampling was done in the boulder field on the south-east corner of the rock platform where the boulders are moderately exposed to the dominant south-easterly swell (as in Chapman 2005). The boulders are composed predominately of shale and rest on similar substratum to that at Cape Banks and Clovelly Bay.

At Cape Banks in February 2003, 20 haphazardly chosen boulders were lifted vertically or overturned (depending on their size and the surrounding area), and all Heliocidaris visible on the undersurface of or below each boulder were counted. The upper size limit was a boulder that could be replaced in its original position without extreme disturbance and dislodgment (Chapman \& Underwood 1996).

To evaluate the generality of patterns found at Cape Banks, boulder fields at Clovelly Bay and Long Reef were sampled similarly in February and July 2003, respectively, although the number of boulders sampled was increased to 30 . To evaluate the temporal ge- 


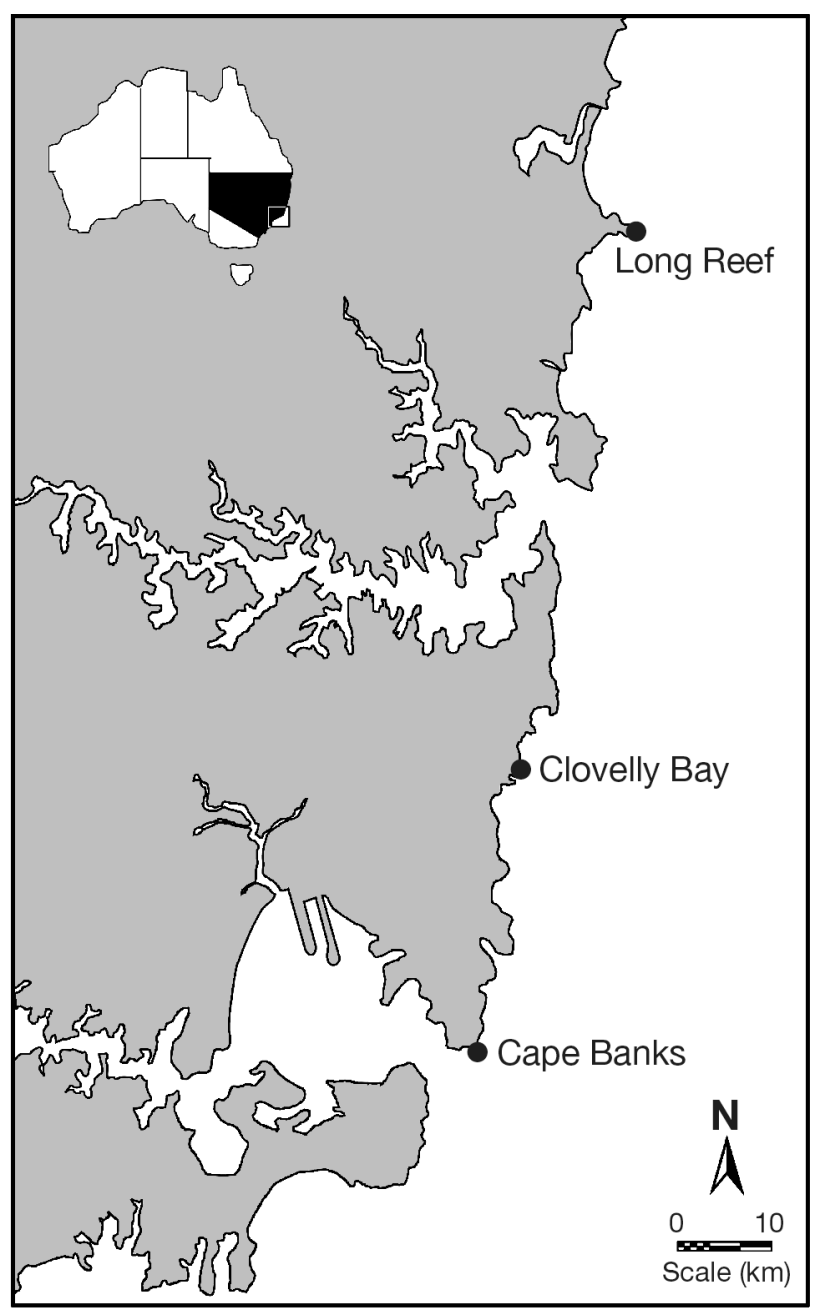

Fig. 1. Study sites on the coast of New South Wales, Australia

nerality of these patterns, the boulder fields at Cape Banks and Clovelly Bay were re-sampled 1 mo (March) and 5 mo (July) after the initial sampling, using similar methods and $\mathrm{n}=30$.

Analyses showed that Heliocidaris were significantly aggregated under few of the available boulders (see Results). To evaluate the model that patterns of recruitment maintain this pattern, 2 hypotheses were tested. The first was that Heliocidaris will recruit in greater numbers to boulders already occupied by adult and juvenile Heliocidaris than to boulders without urchins. Second, new recruits will arrive on a greater proportion of those boulders that have adult and/or juvenile urchins than is the case for boulders without urchins. Recruits of Heliocidaris were defined as $<1.5 \mathrm{~cm}$ in test diameter, as this was the size at which individuals could be first observed without destructive sampling of the boulders. It therefore encompasses patterns of settlement and early mortality and/or movement (Keough \& Downes 1982). To test these hypotheses, 30 boulders with urchins (test diameter $>1.5 \mathrm{~cm}$ ) and 30 boulders without urchins of this size were haphazardly chosen from available boulders in Clovelly Bay and Long Reef. The undersurface of each boulder was searched exhaustively for Heliocidaris $<1.5 \mathrm{~cm}$ test diameter in June and July 2003 at Clovelly Bay and in July at Long Reef.

To evaluate the models that the above patterns may be established and/or maintained by juvenile and adult Heliocidaris (i.e. $>1.5 \mathrm{~cm}$ test diameter) moving among boulders in response to: (1) features of the boulders, (2) cues associated with conspecifics or (3) some combination of the two, hypotheses about the rates of colonisation and dispersal of adult Heliocidaris to and from the 2 types of boulders (boulders originally with urchins and boulders originally without urchins) were tested (Table 1). The above factors have the potential to affect the number of Heliocidaris per boulder and the number of boulders that are occupied by Heliocidaris within the boulder field. Model 1 predicts that if Heliocidaris respond to features of boulders, then: $\left(\mathrm{H}_{1}\right)$ more Heliocidaris will colonise boulders from which Heliocidaris are removed (+UB - U) than boulders originally without urchins (-UB). It also predicts $\left(\mathrm{H}_{2}\right)$ that a greater proportion of boulders from which Heliocidaris have been removed (+UB - U) will be re-occupied by Heliocidaris than will boulders originally without urchins (-UB). Furthermore, $\left(\mathrm{H}_{3}\right)$ if Heliocidaris are transplanted from boulders with urchins to boulders without urchins, they will leave at a faster rate than they leave boulders originally occupied by urchins. Similarly, $\left(\mathrm{H}_{4}\right)$ proportionally more unoccupied boulders (-UB) to which Heliocidaris have been experimentally added will lose urchins than will boulders originally occupied by adult urchins (+UB).

Alternatively, if only the presence of conspecifics influences the observed pattern, then $\left(\mathrm{H}_{5}\right)$ if Heliocidaris are removed from boulders originally with urchins (+UB - U) and boulders originally without urchins (-UB) are left undisturbed, Heliocidaris will not colonise either type of boulder. In addition, $\left(\mathrm{H}_{6}\right)$ if Heliocidaris are transplanted to unoccupied boulders, they will leave these boulders $(-\mathrm{UB}+\mathrm{U})$ at the same rate as they leave boulders originally occupied by adults, but from which other urchins are removed (+UB - U). Similarly, $\left(\mathrm{H}_{7}\right)$ there will be no difference between the proportions of boulders that lose urchins irrespective of whether they were originally occupied by urchins. To test these hypotheses, we used the following treatments: (1) boulders originally with urchins (+UB), (2) boulders originally with urchins but from which urchins had been experimentally removed (+UB - U), (3) boulders originally without urchins (-UB) and (4) boulders originally without urchins but to which urchins 
Table 1. Heliocidaris erythrogramma. Summary of models and hypotheses required to test the hypotheses about (a) colonisation and (b) dispersal to and from different types of boulders

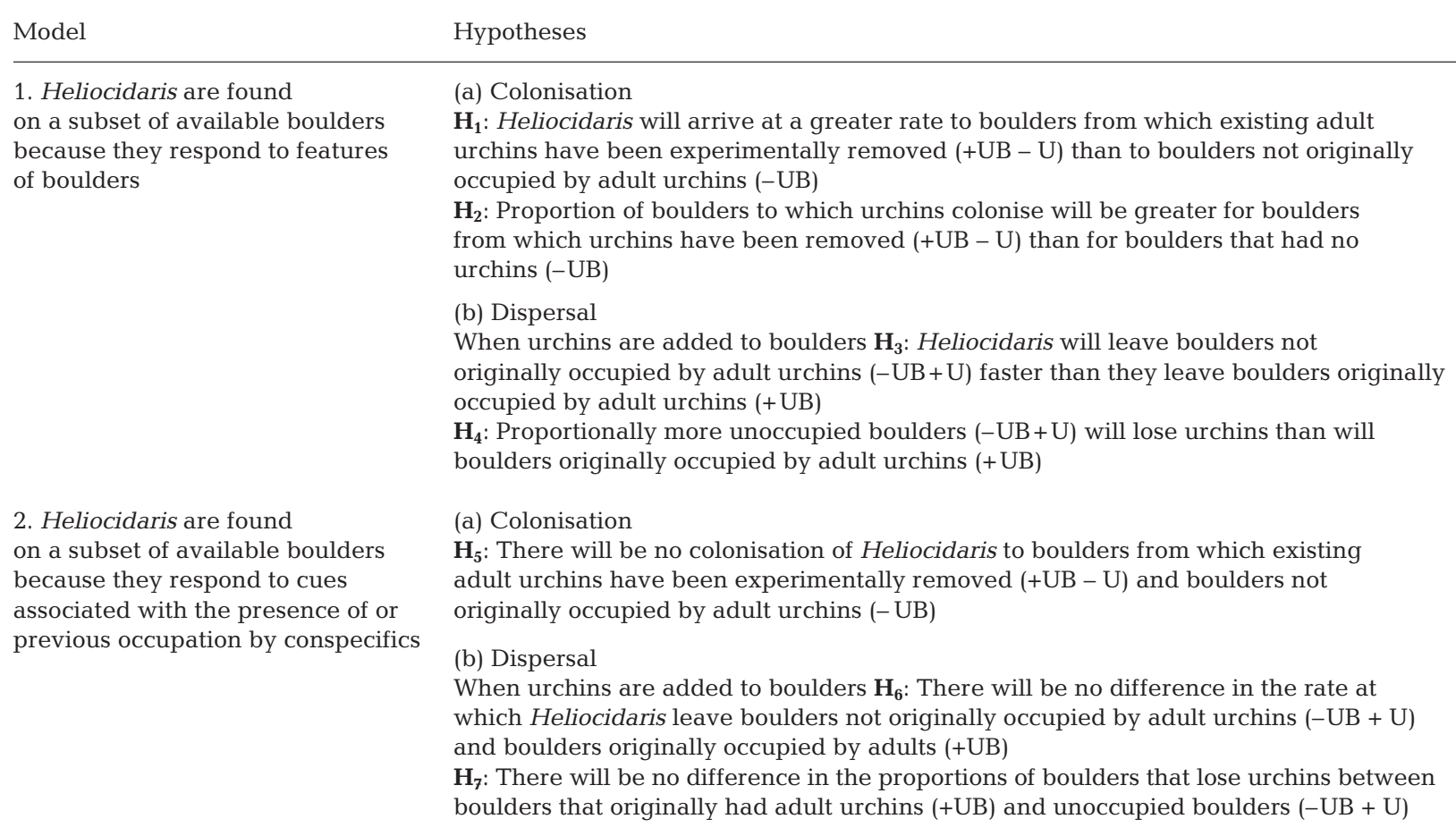

were experimentally added (-UB + U) (Table 2). Moreover, to differentiate between those urchins that colonise boulders from those individuals originally left on boulders, urchins required tags. Due to excessive disturbance associated with tagging individuals and leaving boulders overturned or repeatedly overturning them (Chapman \& Underwood 1996) while urchins were being tagged (A. F. Smoothey unpubl. data), this procedure was not incorporated in the present study. All urchins used in the experiments were carefully removed from the boulder by hand to minimise injury to the animals and disturbance to the substrata under the boulder. Urchins were held in place on the undersurface of their respective boulder, and all urchins re-attached themselves within $2 \mathrm{~min}$. Experimental manipulations were completed on $1 \mathrm{~d}$.

The experiments were started at Clovelly Bay on 13 June 2003. Preliminary sampling showed that Heliocidaris colonised and dispersed from boulders after just $1 \mathrm{~d}$. The boulders in this study were therefore sampled, and the number of Heliocidaris under each boulder was recorded $1 \mathrm{~d}, 7 \mathrm{~d}$ and $14 \mathrm{~d}$ after the start of the experiment. Times of sampling were not independent because the same boulders were sampled each time.

To evaluate the temporal generality of these experiments, they were repeated on 12 July 2003 at Clovelly

Table 2. Heliocidaris erythrogramma. Treatments used to test the hypotheses about colonisation and dispersal to and from different types of boulders, and to test for experimental artefacts associated with transplanting to boulders originally without urchins $(-\mathrm{UB}+\mathrm{U})$. +UB - U: removal of Heliocidaris from boulders with urchins; -UB: unmanipulated boulders originally without urchins; -UB + U: Heliocidaris transplanted to boulders originally without urchins; $+\mathrm{UB}+\mathrm{U}$ : Heliocidaris translocated from boulders with urchins to unfamiliar boulders with urchins; +UBD: disturbed Heliocidaris under boulders with urchins; +UB: unmanipulated Heliocidaris under boulders with urchins; $\checkmark$ : treatment used; $X$ : treatment not used

\begin{tabular}{|c|c|c|c|c|c|c|}
\hline \multirow[t]{2}{*}{ Procedure } & \multicolumn{2}{|c|}{ —Colonisation- } & \multicolumn{4}{|c|}{$\longrightarrow$ Dispersal } \\
\hline & $+\mathrm{UB}-\mathrm{U}$ & $-\mathrm{UB}$ & $-\mathrm{UB}+\mathrm{U}$ & $+\mathrm{UB}+\mathrm{U}$ & +UBD & $+\mathrm{UB}$ \\
\hline Disturbed & $x$ & $x$ & $\checkmark$ & $\checkmark$ & $\checkmark$ & $x$ \\
\hline $\begin{array}{l}\text { Moved to an } \\
\text { unfamiliar boulder } \\
\text { with urchins }\end{array}$ & $x$ & $x$ & $\checkmark$ & $\checkmark$ & $x$ & $x$ \\
\hline $\begin{array}{l}\text { Moved to a boulder } \\
\text { without urchins }\end{array}$ & $x$ & $x$ & $\checkmark$ & $x$ & $x$ & $x$ \\
\hline Removed from & & & & & & \\
\hline boulders with urchins & $\checkmark$ & $x$ & $x$ & $x$ & $x$ & $x$ \\
\hline
\end{tabular}



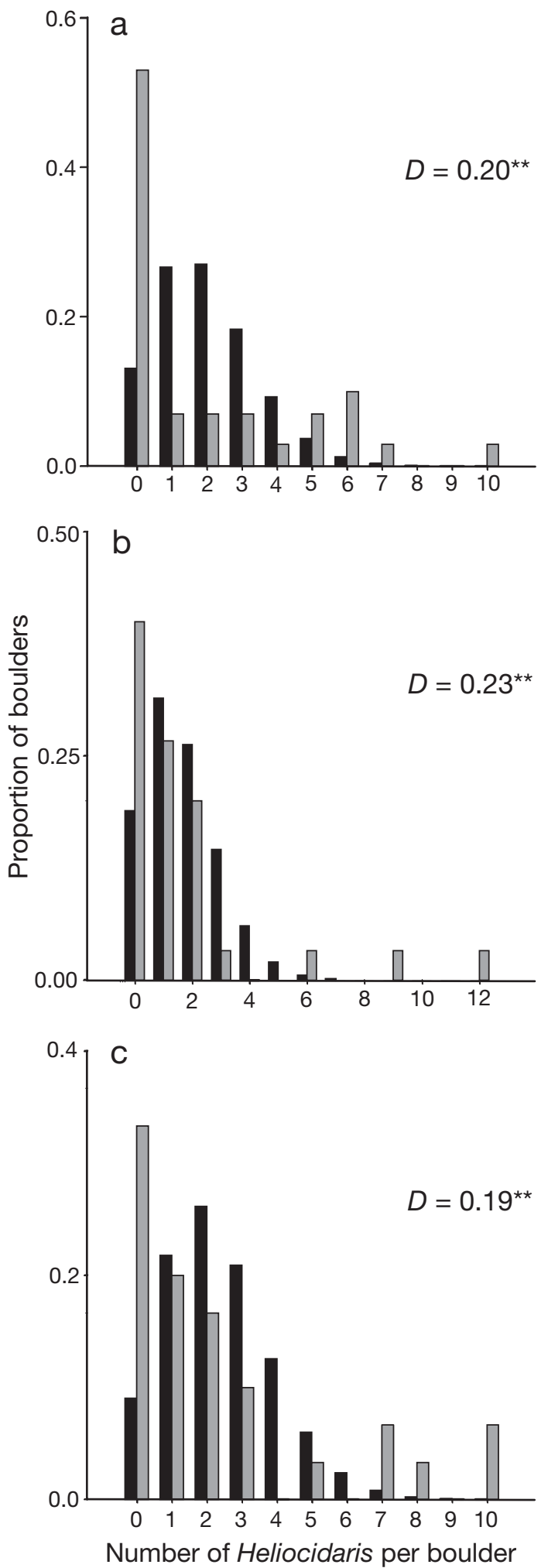

Fig. 2. Heliocidaris erythrogramma. Observed distribution (grey bars) of boulders and the expected (Poisson) distribution (black bars) for (a) Cape Banks, (b) Clovelly Bay and (c) Long Reef; $\mathrm{n}=30$ boulders. $D$ is the test statistic for KolmogorovSmirnov tests. ${ }^{* *}$ Distributions were significantly different at $\mathrm{p}<0.01$
Bay, although the number of boulders per treatment was increased to 15 to increase the power of the experiment. Due to the limited number of boulders with urchins, previously tagged boulders that did not have their density manipulated were re-used, although they were randomly allocated to new treatments. This minimised the possibility of confounding the past history with the effect of the treatment. The experiment was also done at Long Reef on 30 July 2003. Prior to starting the experiment, 15 boulders with urchins and 15 boulders without urchins were tagged. Due to the limited number of boulders without urchins, hypotheses about the dispersal of urchins from the 2 types of boulders were not tested at Long Reef.

\section{RESULTS}

In each boulder field and at each time of sampling, Heliocidaris were not randomly distributed among boulders, but aggregated under some boulders and were absent from others (Fig. 2). Compared to a Poisson distribution, there were more boulders with no Heliocidaris and more boulders with relatively large numbers of Heliocidaris than expected (KolmogorovSmirnov tests, $\mathrm{p}<0.01$ ).

\section{Processes that may act to establish and/or maintain the observed pattern}

\section{Recruitment}

There were significantly more recruits of Heliocidaris on boulders with urchins with test diameter $>1.5 \mathrm{~cm}(+\mathrm{UB})$ than on boulders without urchins of this size (-UB), in each boulder field and at each time of sampling. Mean ( $+\mathrm{SE} ; \mathrm{n}=30$ boulders) numbers of recruits were: Clovelly Bay, 10 June 2003: +UB 1.20 (0.28), -UB 0.27 (0.13), $t=0.002, \mathrm{p}<0.01 ; 8$ July 2003: +UB 1.43 (0.21), -UB 0.47 (0.16), $t=0.003, \mathrm{p}<0.01$; Long Reef, 9 July 2003: +UB 1.03 (0.34), -UB 0.23 (0.10), $t=0.01, \mathrm{p}<0.05$.

Furthermore, during each time of sampling and in each boulder field, the proportion of boulders with urchins $(+\mathrm{UB})$ that were colonised by recruits of Heliocidaris $(<1.5 \mathrm{~cm})$ was significantly greater than the proportion of boulders without urchins (-UB) colonised by recruits (Clovelly Bay, 10 June 2003: proportion of $n$ $=30+\mathrm{UB}$ with recruits $=0.63$, proportion of $\mathrm{n}=30-\mathrm{UB}$ with recruits $=0.16, \chi^{2}{ }_{1}=13.61, \mathrm{p}<0.001 ; 8$ July 2003: proportion of $\mathrm{n}=30+\mathrm{UB}$ with recruits $=0.57$, proportion of $\mathrm{n}=30-\mathrm{UB}$ with recruits $=0.30, \chi^{2}{ }_{1}=20.40, \mathrm{p}<$ 0.001; Long Reef, 9 July 2003: proportion of $n=30+U B$ with recruits $=0.47$, proportion of $\mathrm{n}=30-\mathrm{UB}$ with 
recruits $\left.=0.17, \chi^{2}{ }_{1}=25.75, \mathrm{p}<0.001\right)$. Nevertheless, urchins did recruit to boulders that did not have adult urchins at the start of the experiment.

\section{Behavioural responses of juvenile and adult} Heliocidaris

On each day of sampling $(1,7$ and $14 \mathrm{~d}$ after the experimental manipulation) at Clovelly Bay, the mean number of juvenile and adult Heliocidaris that colonised boulders from which urchins had been removed (+UB - U) was significantly greater than the number that colonised boulders without urchins (-UB; Fig. 3, Table 3a). When the experiment was repeated at Clovelly Bay and conducted at Long Reef, similar results were obtained (Fig. 3, Table 3b,c).

The mean proportional loss in numbers of Heliocidaris that had been transplanted to boulders without urchins $(-\mathrm{UB}+\mathrm{U})$ was significantly greater than for those translocated to boulders with urchins $(+\mathrm{UB}+\mathrm{U})$. In addition, there were no artefacts of translocating Heliocidaris to an unfamiliar boulder, nor disturbing them (Fig. 4; 13 June 2003: Day 1, $F_{3,36}=5.67, \mathrm{p}<0.01 ;$ Day $7, F_{3,36}=11.51, \mathrm{p}<$ 0.001; Day 14, $\left.F_{3,36}=15.73, \mathrm{p}<0.001\right)$. The mean proportional change of Heliocidaris per boulder on each day of sampling was analysed as $\ln (x+2)$ of the net change in the number of Heliocidaris under boulders from the start of the experiment to each day of sampling. Net change $=\left(N_{\mathrm{D}}-N_{\mathrm{S}}\right) / N_{\mathrm{S}}$ where $N_{\mathrm{D}}$ is the number of Heliocidaris under each boulder on each day of sampling $\mathrm{D}$ and $N_{\mathrm{S}}$ is the number of Heliocidaris under each boulder at the start of the experiment. The actual rates of gain or loss of individuals cannot be known, because Heliocidaris were not tagged individually, to avoid excessive disturbance to the urchins and boulders.

When the experiment was repeated at Clovelly Bay, the number of boulders per treatment was increased to 15. After 1, 7 and $14 \mathrm{~d}$, the mean proportional net loss in the numbers of Heliocidaris that had been transplanted to boulders without urchins (-UB + $\mathrm{U})$ was significantly greater than the loss from other treatments, which did not differ significantly from each other (Fig. 4; 12 July 2003: Day $1, F_{3,56}=3.44, \mathrm{p}<0.05 ;$ Day $7, F_{3,56}=$ 10.85, p < 0.001; Day 14, $\left.F_{3,56}=7.10, \mathrm{p}<0.01\right)$.

Similarly, the proportion of boulders originally with urchins (+UB) that were re-occu- pied by Heliocidaris was significantly greater than the proportion of boulders without urchins (-UB) that were subsequently occupied by Heliocidaris on each days of sampling (Day 1, $\chi^{2}{ }_{1}=7.03, \mathrm{p}<0.05$; Day 7, $\chi^{2}{ }_{1}=7.03$, $\mathrm{p}<0.05$; Day 14, $\left.\chi^{2}{ }_{1}=12.86, \mathrm{p}<0.01\right)$. Results were similar at Long Reef (Fig. 3; Day 1, no data; Day 7, $\chi^{2}{ }_{1}=7.50, \mathrm{p}<0.05$; Day 14, $\chi^{2}{ }_{1}=13.61, \mathrm{p}<0.001$ )and when the experiment was repeated at Clovelly Bay (Day 1, $\chi^{2}{ }_{1}=6.14, \mathrm{p}<0.05$; Day 7, $\chi^{2}{ }_{1}=20.0, \mathrm{p}<0.001$; Day $\left.14, \chi^{2}{ }_{1}=22.53, \mathrm{p}<0.001\right)$.

Furthermore, when Heliocidaris were transplanted to boulders that did or did not have urchins, the proportion of boulders with a net loss of Heliocidaris was greater for boulders that did not originally have ur-

Clovelly Bay

Long Reef

a $1 \mathrm{~d}$ after experimental manipulation
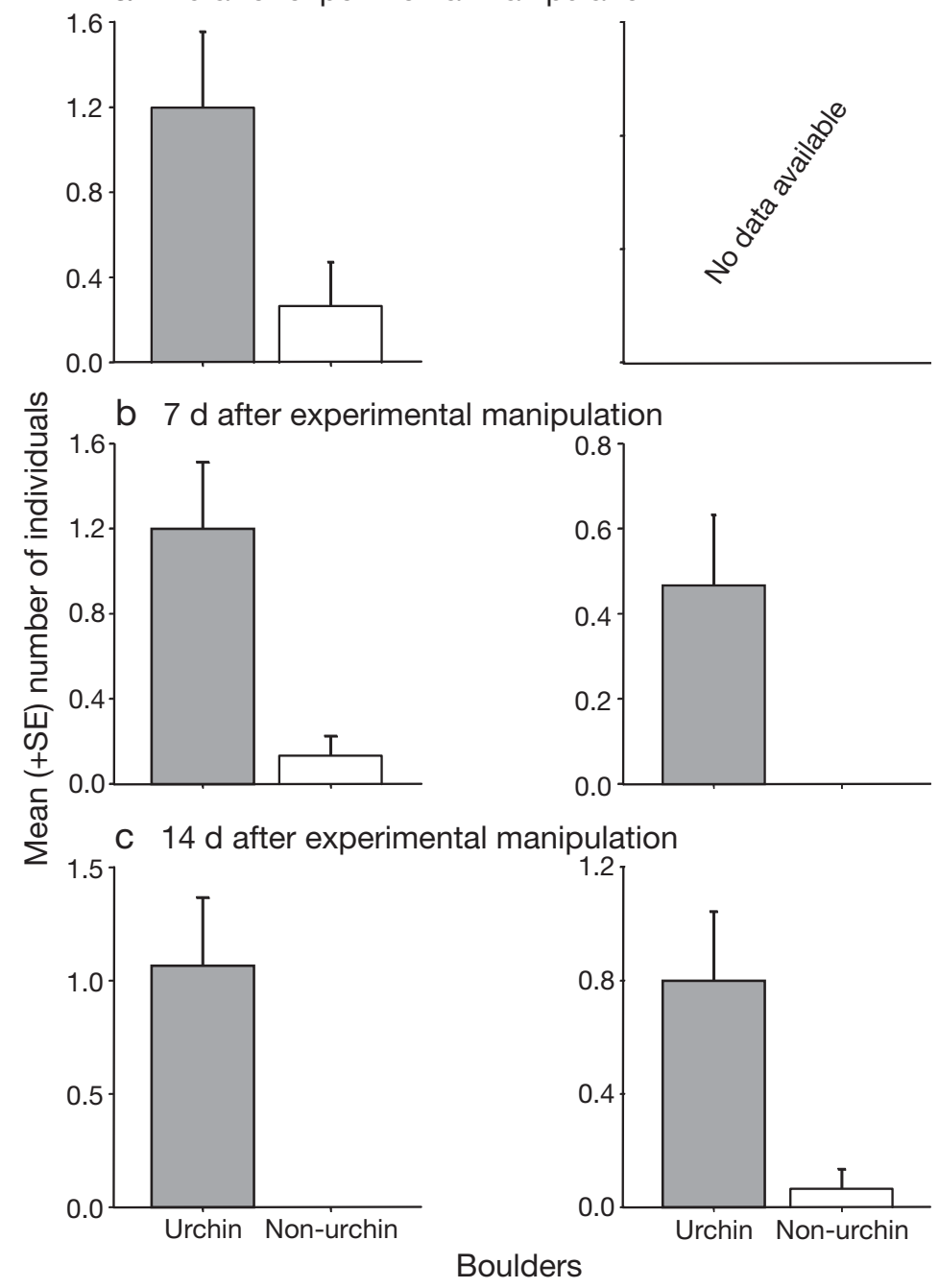

Fig. 3. Heliocidaris erythrogramma. Mean number $(+\mathrm{SE})$ of adults that colonised 15 boulders originally with urchins (+UB) and 15 boulders originally without urchins (-UB) at Clovelly Bay on 13 June 2003 and Long Reef on 30 July 2003 
Table 3. Heliocidaris erythrogramma. Analyses of the mean number of Heliocidaris that colonised boulders: (1) originally with urchins from which Heliocidaris were experimentally removed (+UB - U) and (2) originally without urchins (-UB) at (a) Clovelly Bay on 13 June, (b) Clovelly Bay on 12 July and (c) Long Reef on 30 July. The factor treatment is fixed with $n=15 ; \mathrm{ns}$ : $\mathrm{p}>0.05$; ${ }^{*} \mathrm{p}<0.05,{ }^{* *} \mathrm{p}<0.01,{ }^{* * *} \mathrm{p}<0.001$

\begin{tabular}{|c|c|c|c|c|}
\hline \multirow[t]{2}{*}{ Source } & \multirow[t]{2}{*}{ df } & $1 \mathrm{~d}$ after manipulation & $7 \mathrm{~d}$ after manipulation & $14 \mathrm{~d}$ after manipulation \\
\hline & & MS $\quad F$ & MS $\quad F$ & MS $\quad F$ \\
\hline \multicolumn{5}{|l|}{ (a) } \\
\hline Cochran's test & & $C=0.75 \mathrm{~ns}$ & $C^{\mathrm{a}}=0.75 \mathrm{~ns}$ & $C=1.00^{* * *}$ \\
\hline Treatment & 1 & $6.53 \quad 5.18^{*}$ & $2.43 \quad 10.03^{*}$ & $12.62^{*}$ \\
\hline Residual & 28 & 1.26 & 0.24 & 0.68 \\
\hline Total & 29 & & & \\
\hline SNK & & $+\mathrm{UB}-\mathrm{U}>-\mathrm{UB}$ & $+\mathrm{UB}-\mathrm{U}>-\mathrm{UB}$ & $+\mathrm{UB}-\mathrm{U}>-\mathrm{UB}$ \\
\hline \multicolumn{5}{|l|}{ (b) } \\
\hline Cochran's test & & $C=0.83^{* *}$ & $C=1.00^{* *}$ & $C=0.61 \mathrm{~ns}$ \\
\hline Treatment & 1 & $3.33 \quad 4.22^{*}$ & $13.33 \quad 28.00^{* * *}$ & $7.07 \quad 82.53^{* * *}$ \\
\hline Residual & 28 & 0.79 & 0.47 & 0.09 \\
\hline Total & 29 & & & \\
\hline SNK & & $+\mathrm{UB}-\mathrm{U}>-\mathrm{UB}$ & $+\mathrm{UB}-\mathrm{U}>-\mathrm{UB}$ & $+\mathrm{UB}-\mathrm{U}>-\mathrm{UB}$ \\
\hline \multicolumn{5}{|l|}{ (c) } \\
\hline Cochran's test & & No data & $C=1.00^{* *}$ & $C=0.93^{* *}$ \\
\hline Treatment & 1 & & $1.63 \quad 7.98^{*}$ & $4.03 \quad 8.47^{*}$ \\
\hline Residual & 28 & & 0.20 & 0.48 \\
\hline Total & 29 & & & \\
\hline SNK & & & $+\mathrm{UB}-\mathrm{U}>-\mathrm{UB}$ & $+\mathrm{UB}-\mathrm{U}>-\mathrm{UB}$ \\
\hline
\end{tabular}

chins than for boulders that did. This result was consistent on all days of sampling (Day $1, \chi^{2}{ }_{1}=6.11, \mathrm{p}<0.05$; Day $7, \chi^{2}{ }_{1}=9.86, \mathrm{p}<0.01$; Day 14, $\chi^{2}{ }_{1}=7.12, \mathrm{p}<0.01$ ) and similar results were obtained when the experiment was repeated 1 mo later at Clovelly Bay (Day 1, $\chi^{2}{ }_{1}=5.6, \mathrm{p}<0.05 ;$ Day 7, $\chi^{2}{ }_{1}=8.13, \mathrm{p}<0.01$; Day 14, $\chi^{2}{ }_{1}$ $=5.14, \mathrm{p}<0.05)$.

\section{DISCUSSION}

Abundances of Heliocidaris were very different among individual boulders, such that Heliocidaris occupied only a subset of the available boulders within a site. This pattern was found consistently at different times and in boulder fields tens of kilometres apart. Aggregated patterns of distribution have similarly been observed for $H$. erythrogramma in South Australia (Connolly 1986) and for other species of urchins elsewhere (e.g. Russo 1979, Andrew \& Stocker 1986). For example, Andrew \& Underwood (1989) showed that adult Centrostephanus rodgersii were aggregated within crevices in barren areas during hours of daylight. Similar small-scale patterns of dispersion have also been documented for other taxa living under intertidal and shallow subtidal boulders (see Chapman \& Underwood 1996, Chapman 2005). For example, Grayson \& Chapman (2004) found that all chitons of the genus Ischnochiton were extremely overdispersed among boulders, such that most of the boulders available were not occupied by chitons, but some boulders had very large abundances of individuals.

Patchy patterns of dispersion of organisms have frequently been explained in terms of variation in patterns of recruitment (e.g. Balch \& Scheibling 2000), mortality (e.g. Connell 1961) or behavioural responses of adults to habitat and/or to conspecifics (e.g. Crowe 1996). Heliocidaris recruited in greater numbers to boulders with urchins than to boulders without urchins, and more boulders with adult urchins were colonised by recruits than were boulders without adult urchins. This suggests that recruitment contributes to differences in the dispersion of Heliocidaris among boulders. It does not, however, distinguish between responses of recruits to particular boulders (i.e. habitat) and/or presence of conspecifics. Each of these factors has been shown to affect other taxa (e.g. Tegner \& Dayton 1977). If urchins had recruited to the experimental treatments designed to test hypotheses about colonisation and dispersal, we would have been able to distinguish among these factors. Unfortunately, the experiments were conducted after recruitment. Furthermore, we could not maintain the experimental treatments over periods long enough to quantify recruitment at subsequent times because adults clearly moved among boulders, thereby changing the classifi- 


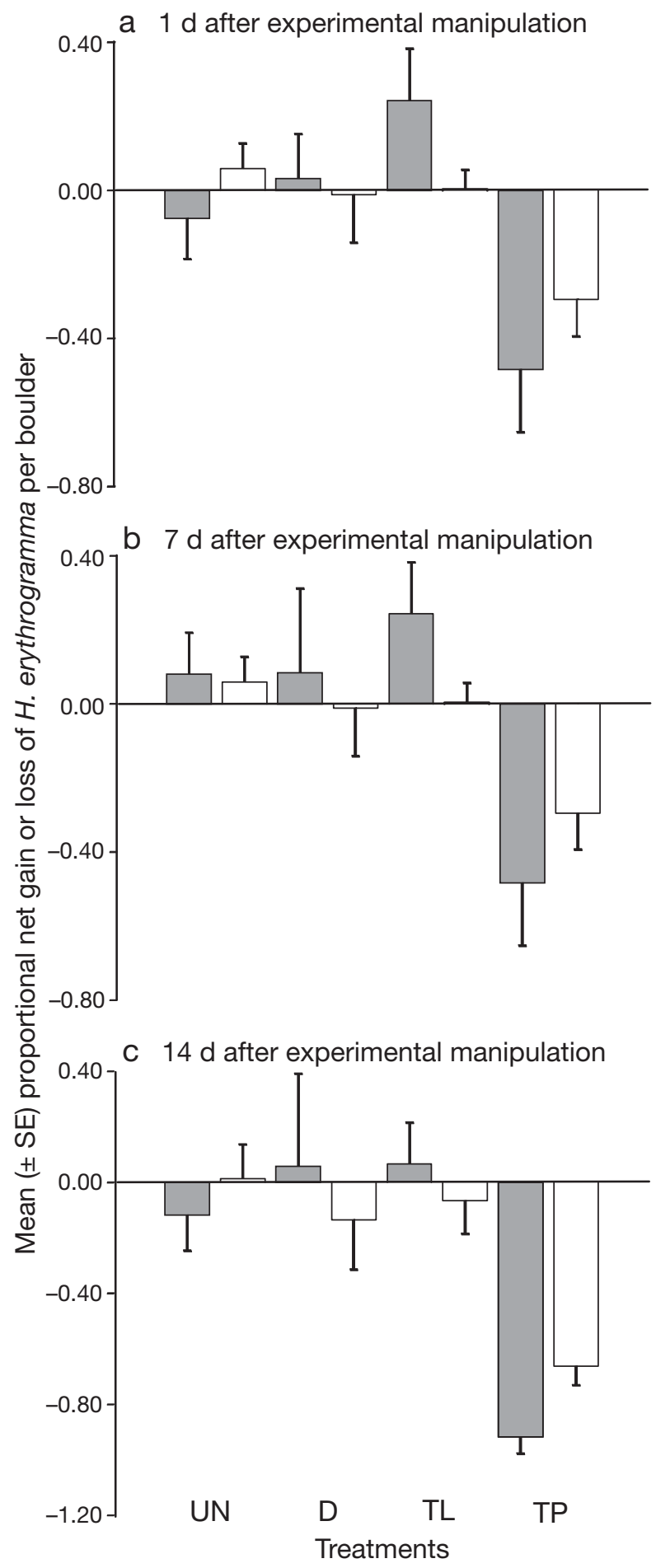

Fig. 4. Heliocidaris erythrogramma. Mean $( \pm$ SE) proportional net change in the number of juveniles and adults per boulder in each treatment at Clovelly Bay on 13 June 2003 ( $\mathrm{n}=10$ boulders; grey bars) and Clovelly Bay on 12 July 2003 ( $n=15$ boulders; white bars). UN: undisturbed Heliocidaris under boulders originally with urchins; D: disturbed Heliocidaris under boulders originally with urchins; TL: boulders with urchins that had Heliocidaris translocated from other boulders with urchins; TP: boulders originally without urchins that had Heliocidaris added from boulders with urchins cation of the boulder. Therefore, we do not know how long boulders originally without urchins had no urchins and further what period of time urchins had been on boulders originally with urchins.

Nonetheless, few studies have specifically shown the relative importance of events early in the life cycle of echinoids in determining patterns of adult distributions (but see Andrew \& Underwood 1989, Andrew \& Choat 1985), or have been done at the small, within-habitat scale, such as the one presented here. While this study has shown that the overdispersion of Heliocidaris among boulders may be established early in the animals' life cycle, it is also not known whether larvae arrive in greater numbers under boulders with urchins than under boulders without urchins, or whether, similar to other echinoderms, larvae settle randomly and then succumb to differential rates of mortality (Rowley 1990) or migration (Mercier et al. 2000).

Juvenile and adult animals may also establish and/or maintain patterns of dispersion by their movements around habitats. Animals may react: (1) positively to 'favoured habitat', (2) negatively to 'unfavoured' habitat, or (3) positively to 'favoured' habitat and negatively to 'unfavoured' habitat. Past studies (e.g. Carefoot 1979) have often assumed that because a species is more abundant in a particular habitat, it prefers to be in that habitat, or that it has actively 'selected' it and rejected other available habitats. These studies often fail to define 'preference' (but see Crowe \& Underwood 1998). Before conclusions can be drawn about an animal's 'preference', it is first essential to experimentally test models about aspects of movement of the animal to explain the observed pattern of distribution. These models are best tested using transplant experiments.

Here, experimental transplants demonstrated that differences in the behavioural responses of juvenile and adult Heliocidaris to particular boulders may strongly influence the dispersion of Heliocidaris among boulders. This includes rates of colonisation and dispersal of adult Heliocidaris to and from the 2 types of boulders, thus affecting the mean number of animals per boulder and the proportion of boulders occupied.

Adult Heliocidaris colonised boulders from which urchins had been experimentally removed (i.e. those that were originally 'suitable' urchin-habitat) at a greater rate than they did boulders originally without urchins. Caution must be taken when interpreting these results, as there may have been remnant chemical cues left by the removed urchins. This experiment could not incorporate a control for this potential cue because it was not possible to know whether removed urchins left some potential unknown cue, nor to remove such a cue without removing urchins. In the 
absence of such controls, it is possible that Heliocidaris colonised boulders originally occupied by urchins because of chemical cues left by conspecifics and/or because of other features of the boulders. Given that Heliocidaris also colonised boulders originally without urchins, the pattern is more dynamic than may be suggested by a single time of sampling. In spite of this, this research along with that of many others (Moran 1985, Chapman \& Underwood 1994) has emphasised the importance of movement, not only in maintaining an animal's distribution, by individuals moving away from potentially 'unfavourable' habitats, but also restoring their distributions when displaced from their normal habitat.

In order to test for generality of ecological processes in addition to patterns, experiments need to be replicated (e.g. Underwood 2000). In this study, the experiments were each done twice; at each time, similar results were found. The hypotheses testing predictions about the effect of colonisation were spatially replicated, but the 2 hypotheses testing predictions about the effect of dispersal could only be replicated in 1 location. There were not enough boulders occupied by Heliocidaris for experimental treatments and appropriate controls at Long Reef. The generality of these results should therefore be interpreted with care. Nonetheless, there is sufficient evidence to suggest that patterns of dispersion of Heliocidaris can be explained by behavioural responses to feature(s) of boulders and/or any cues left by previous urchins.

Boulders vary in abiotic features (e.g. colour, shape, size, composition and complexity), biotic features (e.g. assemblages of sessile and mobile organisms) and features of the surrounding environment (e.g. substratum on which the boulder rests and depth of water), which may influence the patterns of dispersion of Heliocidaris.

James \& Underwood (1994) found that the colour of the boulders influenced the recruitment of spirorbid tubeworms. McGuinness \& Underwood (1986) showed that the complexity of the surface and the material from which the boulder was made significantly affected the number and/or abundance of mobile species that colonised boulders. Similarly, Downes et al. $(2000 \mathrm{a}, \mathrm{b})$ showed that the surface texture of boulders increased species richness of macro-invertebrates on boulders in freshwater systems. Size of boulders can also influence the assemblages associated with boulders by altering rates of disturbance (via overturning or burial) and/or by providing space for species to colonise the boulders (Sousa 1979, Osman 1977, McGuinness 1987). Animals and plants living under boulders are particularly vulnerable to disturbances because of the unstable and complex nature of boulders (Chapman \& Underwood 1996). Physical disturbances to boulders include being moved and or overturned by wave-action or people (Osman 1977, Sousa 1979) and/ or burial by sand and the associated sand-scouring. Although disturbance has been shown to vary at large spatial scales, i.e. among shores, the effects of disturbance may be influenced by small scale variation in features of boulders, such as size (McGuinness 1987) and depth (Osman 1977).

Boulders also vary in the assemblages of sessile and mobile species that live on them (e.g. Sousa 1979, Chapman \& Underwood 1996). Chapman \& Underwood (1996) showed that a diverse assemblage of encrusting and foliose algae, sessile and mobile animals and other materials were associated with intertidal boulders. These organisms and abiotic materials may potentially influence the distribution and abundance of mobile species, by providing favourable conditions, such as food, shelter, or refuge from predators (McGuinness 1988, Downes et al. 2000a,b). McGuinness (1988) showed that mobile organisms, primarily molluscs, colonised boulders with sessile organisms at a faster rate than they did boulders without sessile organisms. He considered that the assemblages of sessile species may be an important source of food for gastropods. The patterns of occupation and colonisation of boulders by Heliocidaris may also be explained by responses to other species that are only present on some boulders; however, Grayson \& Chapman (2004) showed no effect of boulder complexity or sessile assemblages on colonisation by mobile animals.

Andrew \& Stocker (1986) found that the rate of migration of the sea urchin Evechinus chloroticus was a result of manipulating the availability of food, as has been documented for other species of sea urchins (e.g. Russo 1979). While these studies have documented variation in behaviour at larger spatial scales, i.e. between habitats, it is reasonable to suggest that similar processes may operate to determine the observed response of Heliocidaris at small spatial scales, i.e. among individual boulders, if potential food sources are only present on some boulders.

In intertidal and subtidal boulder fields in New South Wales, Heliocidaris appears to demonstrate specific requirements for habitat at small spatial scales, using only a subset of boulders in any place. Understanding the feature(s) of habitat to which Heliocidaris responds will only be possible once more detailed experimental tests are done. This study suggests directions of such tests. Specifically, novel experimental protocols are needed to successfully separate the importance of features of boulders and cues associated with urchins, independent of their presence. Until more is known about the importance of these factors, however, conservation and management of Heliocidaris and its habitat should take account of variation at the small scales identified within this study. 
Acknowledgements. We thank C. A. Styan and A. J. Underwood for their advice throughout this project. Thanks to B. A. Smoothey, J. W. Smoothey and B. J. Lobwein for assistance in the field. Thanks to A. J. Underwood and 3 anonymous referees for helpful comments on an earlier draft of this paper. The research was funded by the Australian Research Council and Centre for Research on Ecological Impacts of Coastal Cities, University of Sydney.

\section{LITERATURE CITED}

Andrew NL, Choat JH (1985) Habitat related differences in the survivorship and growth of juvenile sea urchins. Mar Ecol Prog Ser 27:155-161

Andrew NL, Stocker LJ (1986) Dispersion and phagokinesis in the echinoid Evechinus chloroticus (Val.). J Exp Mar Biol Ecol 100:11-23

Andrew NL, Underwood AJ (1989) Patterns of abundance of the sea urchin Centrostephanus rodgersii (Agassiz) on the central coast of New South Wales, Australia. J Exp Mar Biol Ecol 131:61-80

Archambault P, Bourget E (1996) Scales of coastal heterogeneity and benthic intertidal species richness, diversity and abundance. Mar Ecol Prog Ser 136:111-121

Balch T, Scheibling RE (2000) Temporal and spatial variability in settlement and recruitment of echinoderms in kelp beds and barrens in Nova Scotia. Mar Ecol Prog Ser 205: 139-154

Beisel J, Usseglio-Polatera P, Thomas S, Moreteau J (1998) Steam community structure in relation to spatial variation: the influence of mesohabitat characterisitcs. Hydrobiologia 389:73-88

Benedetti-Cecchi L, Cinelli F (1995) Habitat heterogeneity, sea urchin grazing and the distribution of algae in littoral rock pools on the west coast of Italy (western Mediterranean). Mar Ecol Prog Ser 126:203-212

Benedetti-Cecchi L, Bulleri F, Cinelli F (2000) The interplay of physical and biological factors in maintaining mid-shore and low-shore assemblages on rocky coasts in the northwest Mediterranean. Oecologia 123:406-417

Bulleri F, Benedetti-Cecchi L, Cinelli F (1999) Grazing by the sea urchins Arbacia lixula L. and Paracentrotus lividus Lam. in the Northwest Mediterranean. J Exp Mar Biol Ecol 241:81-95

Carefoot TH (1979) Microhabitat preferences of young Ligia pallasii Brandt (Isopoda). Crustaceana 36:211-214

Chapman MG (2002a) Early colonization of shallow subtidal boulders in two habitats. J Exp Mar Biol Ecol 275:95-116

Chapman MG (2002b) Patterns of spatial and temporal variation of macrofauna under boulders in a sheltered boulder field. Austral Ecol 27:211-228

Chapman MG (2005) Molluscs and echinoderms under boulders: test of generality of patterns of occurrence. J Exp Mar Biol Ecol 325:65-83

Chapman MG, Underwood AJ (1994) Dispersal of the intertidal snail, Nodilittorina pyramidalis, in response to topographic complexity of the substratum. J Exp Mar Biol Ecol 179:145-169

Chapman MG, Underwood AJ (1996) Experiments on effects of sampling biota under intertidal and shallow subtidal boulders. J Exp Mar Biol Ecol 207:103-126

Connell JH (1961) Effects of competition, predation by Thais lapillus, and other factors on natural populations of the barnacle Balanus balanoides. Ecol Monogr 31:61-104

Connell JH (1972) Community interactions on marine rocky intertidal shores. Annu Rev Ecol Syst 3:169-192
Connolly R (1986) Behaviour and ecology of the sea urchin Heliocidaris erythrogramma (Valenciennes). Honours thesis, University of Adelaide

Crowe TP (1996) Different effects of microhabitat fragmentation patterns of dispersal on an intertidal gastropod in two habitats. J Exp Mar Biol Ecol 206:83-107

Crowe TP, Underwood AJ (1998) Testing behavioural "preference" for suitable microhabitat. J Exp Mar Biol Ecol 225: $1-11$

Downes BJ, Lake PS, Schreiber ESG (2000a) What's in a site? Variation in lotic macroinvertebrate density and diversity in a spatially replicated experiment. Austral Ecol 25:128139

Downes BJ, Lake PS, Schreiber ESG, Glaister A (2000b) Habitat structure, resources and diversity: the separate effects of surface roughness and macroalgae on stream invertebrates. Oecologia 123:569-581

Grayson JE, Chapman MG (2004) Patterns of distribution and abundance of chitons of the genus Ischnochiton in intertidal boulder fields. Austral Ecol 29:363-373

Hunt HL, Scheibling RE (1997) Role of early post-settlement mortality in recruitment of benthic marine invertebrates. Mar Ecol Prog Ser 155:269-301

James RJ, Underwood AJ (1994) Influence of colour of substratum on recruitment of sprirorbid tubeworms to different types of intertidal boulders. J Exp Mar Biol Ecol 181: 105-115

Jenkins SR, Aberg P, Cervin G, Coleman RA and 9 others (2000) Spatial and temporal variation in settlement and recruitment of the intertidal barnacle Semibalanus balanoides (L.) (Crustacea: Cirripedia) over a European scale. J Exp Mar Biol Ecol 243:209-225

Keough MJ, Downes BJ (1982) Recruitment of marine invertebrates: the role of active larval choices and early mortality. Oecologia 54:348-352

Loosanoff V (1964) Variations in time and intensity of setting of the starfish, Asterias forbesi, in Long Island Sound during a twenty-five year period. Biol Bull (Woods Hole) 126: 423-439

McGuinness KA (1987) Disturbance and organisms on boulders I. Patterns in the environment and the community. Oecologia 71:409-419

McGuinness KA (1988) Short-term effects of sessile organisms on colonization of intertidal boulders. J Exp Mar Biol Ecol 116:159-175

McGuinness KA, Underwood AJ (1986) Habitat structure and the nature of communities on intertidal boulders. J Exp Mar Biol Ecol 104:97-123

Menge BA, Olson AM (1990) Role of scale and environmental factors in regulation of community structure. Trends Ecol Evol 5:52-57

Mercier A, Battaglene SC, Hamel J (2000) Settlement preference and early migration of the tropical sea cucumber Holothuria scabra. J Exp Mar Biol Ecol 249:89-110

Moran MJ (1985) Distribution and dispersion of the predatory intertidal gastropod Morula marginalba. Mar Ecol Prog Ser 22:41-52

Morrisey DJ, Howitt L, Underwood AJ, Stark JS (1992) Spatial variation in soft-sediment benthos. Mar Ecol Prog Ser 81: 197-204

Osman RW (1977) The establishment and development of a marine epifaunal community. Ecol Monogr 47:37-63

Paine RT, Levin SA (1981) Intertidal landscapes: disturbance and the dynamics of pattern. Ecol Monogr 51:145-178

Raffaelli DG, Hughes RN (1978) The effects of crevice size and availability on populations of Littorina rudis and Littorina neritoides. J Anim Ecol 47:71-83 
Rowley RJ (1990) Newly settled sea urchins in a kelp bed and urchin barren ground: a comparison of growth and mortality. Mar Ecol Prog Ser 62:229-240

Russo AR (1979) Dispersion and food differences between two populations of the sea urchin (Strongylocentrotus franciscanus). J Biogeogr 6:407-414

Smith KA, Otway NM (1997) Spatial and temporal patterns of distribution and the effects of disturbance on under-boulder chitons. Molluscan Res 18:43-57

Sousa WP (1979) Experimental investigations of disturbance and ecological succession in a rocky intertidal algal community. Ecol Monogr 49:227-254

Tegner MJ, Dayton PK (1977) Sea urchin recruitment patterns and implications of commercial fishing. Science 196:324326

Underwood AJ (1984) Vertical and seasonal patterns in competition for microalgae between intertidal gastropods. Oecologia 64:211-222

Editorial responsibility: Roger Hughes (Contributing Editor), Bangor, UK
Underwood AJ (2000) Experimental ecology of rocky intertidal habitats: What are we learning? J Exp Mar Biol Ecol 250:51-76

Underwood AJ, Chapman MG (1996) Scales of spatial patterns of distribution of intertidal invertebrates. Oecologia 107:212-224

Underwood AJ, Denley EJ (1984) Paradigms, explanations and generalizations in models for the structure of intertidal communities on rocky shores. In: Strong DR, Simberloff D, Abele LG, Thistle A (eds) Ecological communities: conceptual issues and the evidence. Princeton University Press, NJ, p 151-180

Wiens JA, Stenseth NC, Van Horne B, Ims RA (1993) Ecological mechanisms and landscape ecology. Oikos 66:369-380

Worthington DG, Fairweather PG (1989) Shelter and food: interactions between Turbo undulatum (Archaeogastropoda: Turbinidae) and coralline algae on rocky seashores in New South Wales. J Exp Mar Biol Ecol 129:61-79

Submitted: August 31, 2006; Accepted: December 11, 2006 Proofs received from author(s): June 5, 2007 